\title{
S. fin
}

\section{Studies in Second Language Learning and Teaching}

Department of English Studies, Faculty of Pedagogy and Fine Arts, Adam Mickiewicz University, Kalisz

\section{Teaching English tense and aspect with the help of cognitive grammar: An empirical study}

\author{
Jakub Bielak \\ Adam M ickiewicz University, Kalisz \\ kubabogu@amu.edu.pl \\ Mirostaw Pawlak \\ Adam M ickiewicz University, Kalisz \\ pawlakmi@amu.edu.pl
}

\begin{abstract}
Form-focused instruction is usually based on traditional practical/pedagogical grammar descriptions of grammatical features. The comparison of such traditional accounts with cognitive grammar (CG) descriptions seems to favor CG as a basis of pedagogical rules. This is due to the insistence of CG on the meaningfulness of grammar and its detailed analyses of the meanings of particular grammatical features. The differences between traditional and CG rules/descriptions are exemplified by juxtaposing the two kinds of principles concerning the use of the present simple and present progressive to refer to situations happening or existing at speech time. The descriptions provided the bases for the instructional treatment in a quasi-experimental study exploring the effectiveness of using CG descriptions of the two tenses, and of their interplay with stative (imperfective) and dynamic (perfective) verbs, and comparing this effectiveness with the value of grammar teaching relying on traditional accounts found in standard pedagogical grammars. The study involved 50 participants divided into three groups, with one of them constituting the control group and the other two being experimental ones. One of the latter received treatment based on CG descriptions and the other on traditional accounts. CG-based instruction was found to be at least moderately effective in terms of fostering mostly explicit grammatical
\end{abstract}


knowledge and its effectiveness turned out be comparable to that of teaching based on traditional descriptions.

Keywords: cognitive grammar, pedagogical grammar, traditional descriptions, tense, aspect

The teaching of second/foreign language grammar $^{1}$ cannot do without descriptions of grammatical elements, which may only be produced with any degree of systematicity with the help of some theoretical assumptions, if not within the confines of some linguistic theory(ies). Although it is rarely openly stated, when viewed from this perspective, most grammatical descriptions employed by language teachers may be said to be traditional in nature. They are usually taken from textbooks, which normally extract information from pedagogical and practical grammars, or from these grammars themselves. As argued by Bielak and Pawlak (in press), pedagogical/practical grammars are normally based on major descriptive/reference grammars such as the ones by Quirk, Greenbaum, Leech, and Svartvik (1985) and Huddleston and Pullum (2002), whose theoretical orientation is referred to by Bielak and Pawlak (in press) as structuralist-traditional. This label is used because, generally speaking, the descriptive/reference grammars employ mostly traditional grammatical terminology and organization of the material, concentrate mostly on language facts rather than their explanations, and provide numerous taxonomies (Bielak \& Pawlak, in press). Because grammatical descriptions used in pedagogy are, through the mediation of textbooks and pedagogical/practical grammars, based on the descriptive/reference grammars, their labeling as traditional seems to be warranted, and the label itself should be viewed as reflecting their structuralist-traditional foundations. However, as evidenced by some pedagogical grammars which state that contemporary linguistics enhances the descriptions they provide (e.g., Celce-Murcia \& Larsen-Freeman, 1999), modern linguistic theory may have a lot to offer to language teachers and, through their mediation, to learners.

One such innovation is cognitive linguistics, which includes cognitive grammar (Langacker, 1987, 1991) as one of its leading theories. The potential relevance of cognitive linguistics and cognitive grammar (CG) to language teaching has been premised mainly on their insistence on the meaningfulness of most areas of language, including grammar, and on the comprehensiveness of their semantic analyses. While there are numerous theoretically-oriented proposals concerning the harnessing of CG in the service of grammatical in-

\footnotetext{
${ }^{1}$ In this paper, no important distinction is made between teaching and learning second and foreign languages.
} 
struction (e.g., Achard, 2008; Niemeier \& Rief, 2008; Turewicz, 2000; Tyler, 2008; Tyler \& Evans, 2001), empirical research testing the effectiveness of such applications is only beginning to appear (e.g., Huong, 2005; KrólMarkefka, 2010; Tyler, Mueller, \& Ho, 2010).

The present article, reporting on one study which is part of a larger research project, ${ }^{2}$ is intended as a contribution to the emerging body of empirical evidence concerned with pedagogical applications of CG. Specifically, its purpose is determining the effectiveness of using CG descriptions of the socalled present simple and present continuous, and of their interplay with stative and dynamic verbs when reference is made to situations unfolding at the time of speaking, and comparing this effectiveness with that of grammar teaching relying on traditional descriptions found in standard pedagogical grammars. Instructional effectiveness is considered in terms of fostering mostly explicit grammatical knowledge. ${ }^{3}$

\section{Descriptions of Selected Facets of the English Tense/ Aspect System}

The present study focuses on teaching the choice between the English progressive and nonprogressive present tense when reference is made to single situations ${ }^{4}$ existing or happening at the time of speaking, which often depends on whether the situation is expressed by a stative or a dynamic verb. For this reason, the present section offers the traditional and CG descriptions of the relevant aspects of the grammatical phenomena involved which were exploited in the treatments of the study, namely the present tense, the progressive aspect and the distinction between the so-called stative and dynamic verbs. This is done to the exclusion of all the other facets and uses of these grammatical elements.

\section{Traditional Descriptions}

The traditional descriptions offered here and used as a basis of instruction in the quasi-experiment described below are taken from two standard practical/pedagogical grammars, namely Eastwood (1999) and MańczakWohlfeld, Nizegorodcew, and Willim (2007). With respect to the use of the

\footnotetext{
${ }^{2} \mathrm{~A}$ more comprehensive description of this project is to be published in two volumes, the first of which is Bielak and Pawlak (in press).

${ }^{3}$ For the exploration of the implicit knowledge dimension see Bielak and Pawlak (in press).

${ }^{4}$ The use of situation as an umbrella term referring to verb-symbolized phenomena, that is, to states, activities, events, actions and processes existing and unfolding in time, follows Quirk et al. (1985, p. 177).
} 
present tense either with or without the progressive when talking about something which exists or is happening now, at the moment of speaking, and in particular when the choice of one of them is at issue, the two sources jointly give the following rules:

1. Stative verbs are not usually used with the progressive ("a state means that something is staying the same" [Eastwood, 1999, p. 14]); dynamic verbs may be used in progressive tenses ("an action means something happening" [Eastwood, 1999, p. 14]); for example, The farmer owns the land, The farmer is buying the land (Eastwood, 1999, p. 14).

2. The present progressive is used to "say that we are in the middle of an action" (Mańczak-Wohlfeld et al., 2007, p. 154), for example, I'm getting the lunch ready (Eastwood, 1999, p. 8). In other words, it is used "to refer to an activity in progress at the very moment of speaking or about the moment of speaking," for example, I am trying to fall asleep (Mańczak-Wohlfeld et al., 2007, p. 154).

3. The nonprogressive present tense is normally used to refer to thoughts, feelings, states and permanent facts, for example, I think it's a good programme, Kitty likes her job (Eastwood, 1999, pp. 10-12). MańczakWohlfeld et al. (2007, p. 155) explain why it is so; the meanings of stative verbs of the following types are incompatible with the progressive:

a. "verbs referring to passive mental states, that is, verbs of inert cognition" (think, believe, etc.), for example, I think it is all right, "as opposed to mental activities," for example, I am thinking about it;

b. "verbs referring to more or less permanent emotions," for example, love, like, and hate;

c. "verbs referring to passive activities of the senses, that is, verbs of inert perception," for example, hear, see, as opposed to listen to, look.

4. The nonprogressive present tense is used with such verbs as promise, agree, and refuse; for example, I promise I'll write to you; It's all right, I forgive you (Eastwood, 1999, pp. 10-12).

5. Sometimes a given verb may be used either for a state or an action and may therefore be used both without and with the progressive, for example, I think you are right versus I am thinking about the problem (Eastwood, 1999, p. 14). Mańczak-Wohlfeld et al. (2007, pp. 156-157) explain what kinds of stative verbs may be used in the progressive and why:

a. They may have a different meaning which is compatible with the progressive; the use of the progressive involves either an activity 
with human agency or a temporary activity, or sometimes both, ${ }^{5}$ for example, I am thinking about it (a temporary, voluntary activity).

b. Some sensation verbs, when used transitively, may be used in the progressive, for example, I am tasting the soup, She is smelling the roses.

c. The progressive may be used with state verbs to imply a gradual change in a state, for example, She is resembling her mother more and more.

6. Sometimes a state verb may be used in the progressive "to talk about a short period of time," for example, I like school versus I'm liking school much better now (Eastwood, 1999, p. 14).

\section{CG Descriptions}

In CG, it is assumed that verbs designate processes, that is, relations between two entities with positive temporal profiles (Langacker, 1987, p. 244), which means that these processes receive a certain amount of focal prominence (they are profiled) and are construed as unfolding through conceived time (they have positive temporal profiles). The conceptualization of such relations requires the employment of a mode of cognitive processing called sequential scanning, which results in the conception of a series of relations transformed sequentially one into another. This characterization of the semantics of verbs makes crucial reference to construal, that is, to (different ways of) viewing semantic content (cf. Langacker, 2008, pp. 55-91), and to cognitive processing, rather than to the contents of conception. CG assumes the division of all verbs into perfective and imperfective ones, with the attendant distinction between perfective and imperfective processes (Langacker, 2002, p. 87). Generally, perfective verbs refer to situations which involve some change and are bounded, while imperfective verbs denote situations which are stable and unbounded.

Because a process is a series of relations scanned sequentially through conceived time, words with processual meanings are devices ideally suited to describing change (Langacker, 1987, p. 254). And indeed, perfective verbs, which constitute the majority of the verb class, refer to a change of some sort (Langacker, 1987, p. 254). Individual relations that these verbs profile are usually not all the same, and the differences between them constitute the change in

\footnotetext{
${ }^{5}$ This rule is worded ambiguously in the grammar by Mańczak-Wohlfeld et al. (2007). The rules given here are partially based on the authors' interpretation of the examples illustrating the rule.
} 
question. Another important characteristic of perfective verbs is that their processes are bounded within the temporal scope of predication (Langacker, 1987, pp. 258-262), that is, within the semantic base needed for the characterization of the process. The essentials of the semantics of perfective verbs are depicted in Figure 1. The component states of a perfective process are represented by the bold line, which is wavy to stress the change that is typically involved. The line, whose every point corresponds to a single relationship, extends along the time arrow, which signals the evolution of the process through conceived time. Vertical bars at the endpoints of the line bound the process and mark its beginning and end, which are both included in the scope of predication.

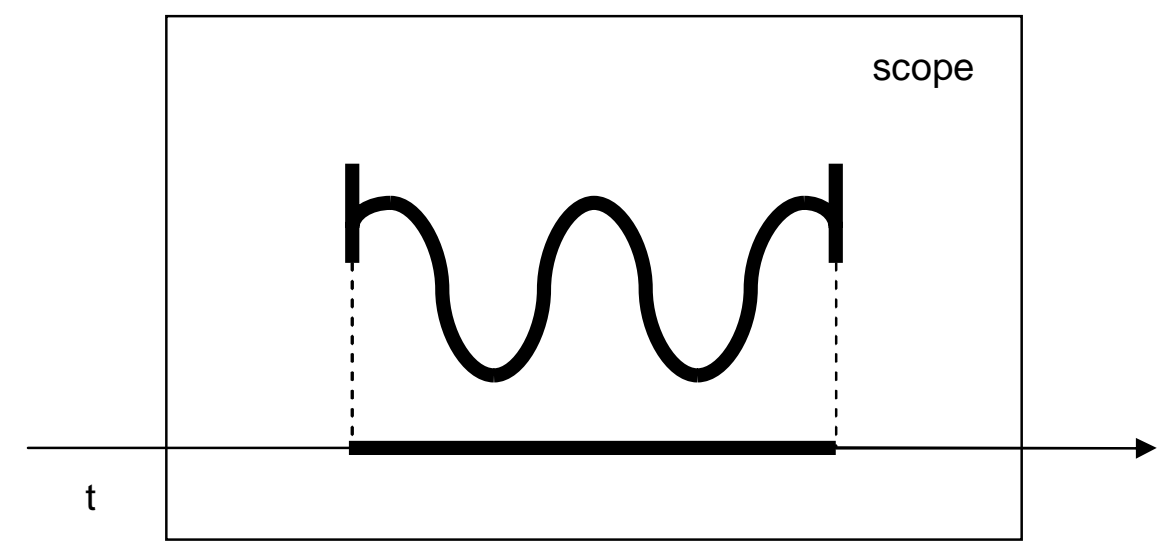

Figure 1 Semantics of perfective verbs (1) (Langacker, 2002, p. 88)

In contrast to perfective ones, imperfective verbs designate processes all the component relations of which are construed as effectively identical, which results in the conception of a stable situation persisting through conceived time (Langacker, 1987, p. 256). Also, because imperfective processes are construed in CG as homogeneous, they are thought to be characterized by inherent expansibility/contractibility, and they are therefore not inherently bounded in their temporal scope (Langacker, 1987, pp. 258-262). Figure 2 highlights the relevant details. The heavy line representing a series of relationships characteristic of processes is straight, which indicates that the relations are construed as the same and that no change is involved. The line is not delimited by vertical bars, which reflects the absence of inherent bounding typical of imperfectives. Instead, the ellipses (...) indicate the indefinite temporal extension of the process, one portion of which, limited by the scope of predication, is profiled. This is expressed by the heavy-line part of the entire line. 


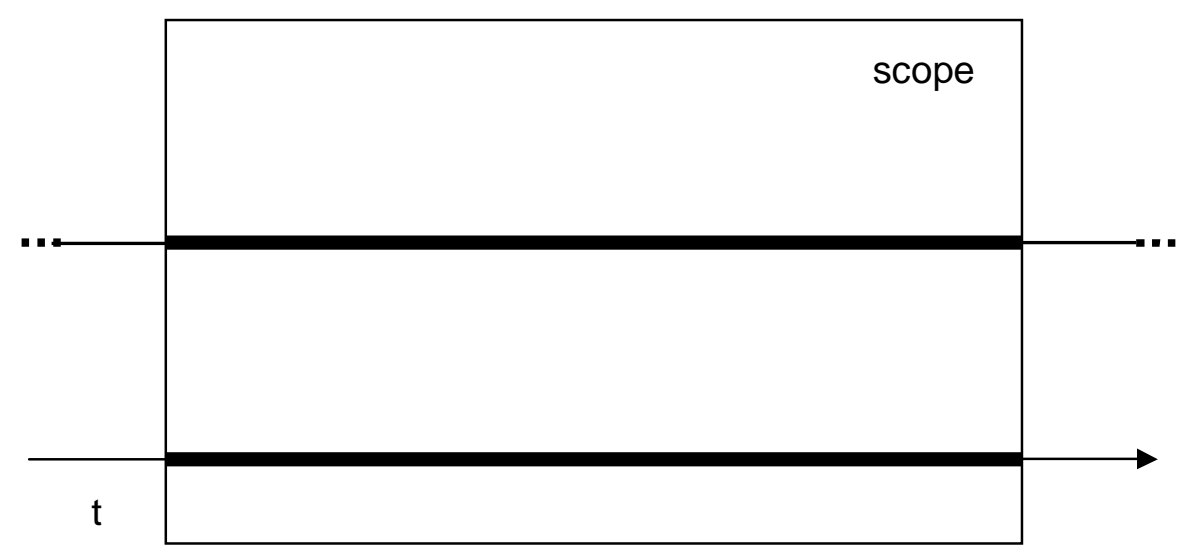

Figure 2 Semantics of imperfective verbs (Langacker, 2002, p. 88)

It should be noted that in CG verbs of either type are regarded as generally flexible in the sense that they often have different variants or senses belonging to two different lexical-aspectual classes: perfective and imperfective. A good example is the verb like as occurring in the sentence I'm liking school much better now offered by Eastwood (1999, p. 14). According to this author, like is a stative verb here and it is used with the progressive to talk about a situation of short duration (Eastwood, 1999, p. 14). In contrast, CG claims that like in such sentences has an extended, perfective sense, because "a period of stability is regarded as a bounded episode rather than something expected to continue indefinitely" (Langacker, 1991, p. 208).

According to traditional accounts (Rule 1 above), only dynamic/ perfective verbs are compatible with the English progressive, while stative/imperfective ones are not. Another widespread view of the progressive is that it takes an internal perspective on a situation (Rule 2), while the nonprogressive views a process from an external perspective, in its entirety (cf. Langacker, 1991, p. 208). Both views are essentially accepted (Langacker, 1991, p. 208) and insightfully explained by CG, which in addition claims that the English progressive is used with perfective verbs to make them imperfective (Langacker, 1991, p. 209).

This transformation from a perfective into an imperfective will now be explained and illustrated by a sequence of figures. First, Figure 3 introduces yet another pictorial CG convention used to represent perfective processes. The circle and the square stand for two processual entities, while the line which links them represents their relation. The sequence of several relations of this sort, including the initial and the terminal ones, stands for a longer sequence constituting the whole process. The processual nature of this configuration is highlighted by the heavy line portion of the time arrow, which sym- 
bolizes sequential scanning. Figure 4 depicts the semantic value of the present participle (-ing), an essential component of the English progressive. In CG, -ing is said to designate a complex nonprocessual relationship which is an internal subpart of a longer process and whose component relations are viewed as effectively identical (Langacker, 1991, p. 209). As can be seen in Figure 4, -ing imposes a restricted immediate scope on a process, which 'pushes' certain of its component relations outside the profile, including the initial and terminal ones (Langacker, 2008, p. 120). All these excluded relations, being outside the immediate scope and thus unprofiled, lose their bold-line marking in Figure 4. Another thing -ing does is to "abstract away from any differences among the focused states, thus viewing them as effectively equivalent" (Langacker, 2008, p. 121). Thus, the highlighted relations are viewed a homogeneous mass, as indicated by the ellipses (...). This is possible because the relations are seen as representative of the whole perfective process (Langacker, 1991, p. 209). The last semantic feature of -ing is that it nullifies sequential scanning characteristic of all verbs, and thus turns a process into a complex atemporal relation (Langacker, 1991, p. 209), that is, a relation which is not scanned sequentially, and is instead viewed holistically. This is signaled in Figure 4 by the disappearance from the time arrow of heavy-lining, in comparison with Figure 3. All of these semantic features of the present participle are also expressed, albeit differently, in Figure 5, which follows the conventions of Figures 1 and 2, and is offered here for the purposes of comparison with them. It abbreviates the semantic value of -ing even more than Figure 4; the heavy straight line within the immediate scope, similar to that in Figure 2, stresses the effective homogeneity of the focused part of an essentially perfective process. Figure 6 shows the effect of combining -ing (together with a verb it attaches to) with the second element of the progressive construction, the verb be. The function of be is to supply sequential scanning, symbolized by the highlighted portion of the time arrow included within the immediate scope. Be thus restores the processual character of the main verb, suspended earlier by -ing (Langacker, 1991, pp. 210-211). ${ }^{6}$

${ }^{6}$ Obviously, the composition of a progressive structure, let alone a whole clause containing it, is much more complex than what has been mentioned here. For instance, it is executed in a number of steps and simultaneously at several levels. All this is simplified and taken for granted here, there being no need in the present context to dwell on the particulars of the whole complex process. For the detailed CG exposition of composition see Langacker (1987, 1991). 


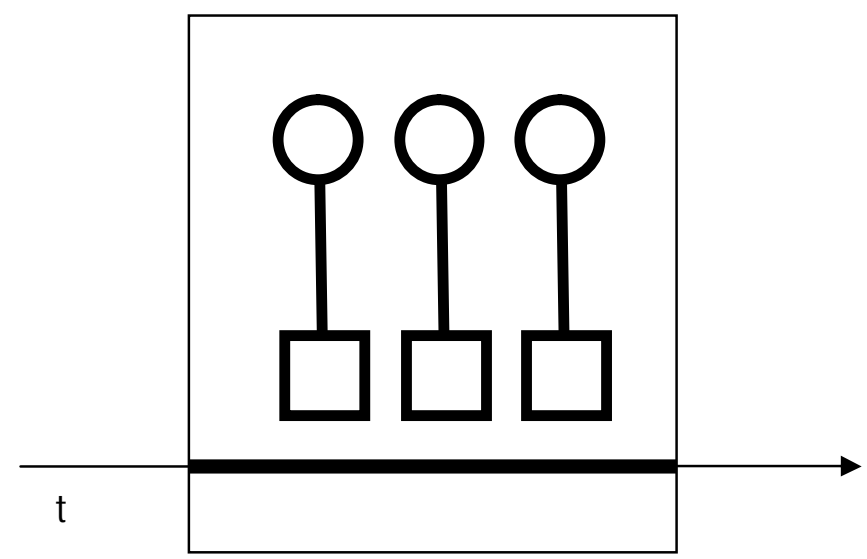

Figure 3 Semantics of perfective verbs (2) (adapted from Langacker, 2008, p. 119)

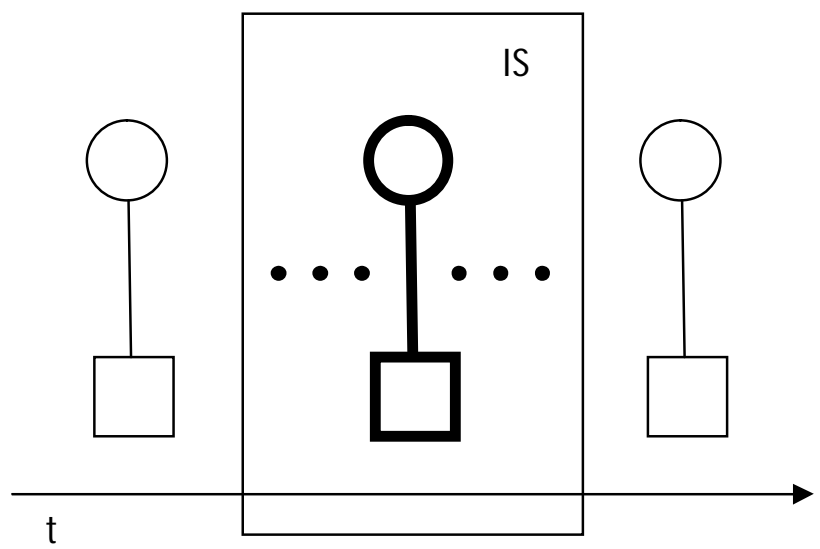

Figure 4 Semantics of -ing (1) (Langacker, 2008, p. 121)

This CG analysis of the semantics of the progressive accounts for a number of its characteristics. First, it explains why the progressive is compatible only with perfective verbs, to the exclusion of imperfectives. For one thing, the redundancy of applying the imperfectivizing progressive to imperfective verbs is conventionally rejected in English (Langacker, 1991, p. 208). Using the imperfectivizing impact of the progressive with perfectives, on the other hand, makes perfect sense since it is not redundant. Second, CG explains the achievement of the internal perspective on a situation associated with the progressive. It is reached through the narrowing down of focus so that the endpoints of a process are no longer in it, which is due to the contribution of -ing. This morpheme is also responsible for the third feature of the progressive, namely its imperfectivizing force itself. This results from -ing's homogenization of the component relations of a process, and from its 
elimination of bounding, which stems from the exclusion of the endpoints of a perfective process from the immediate scope.

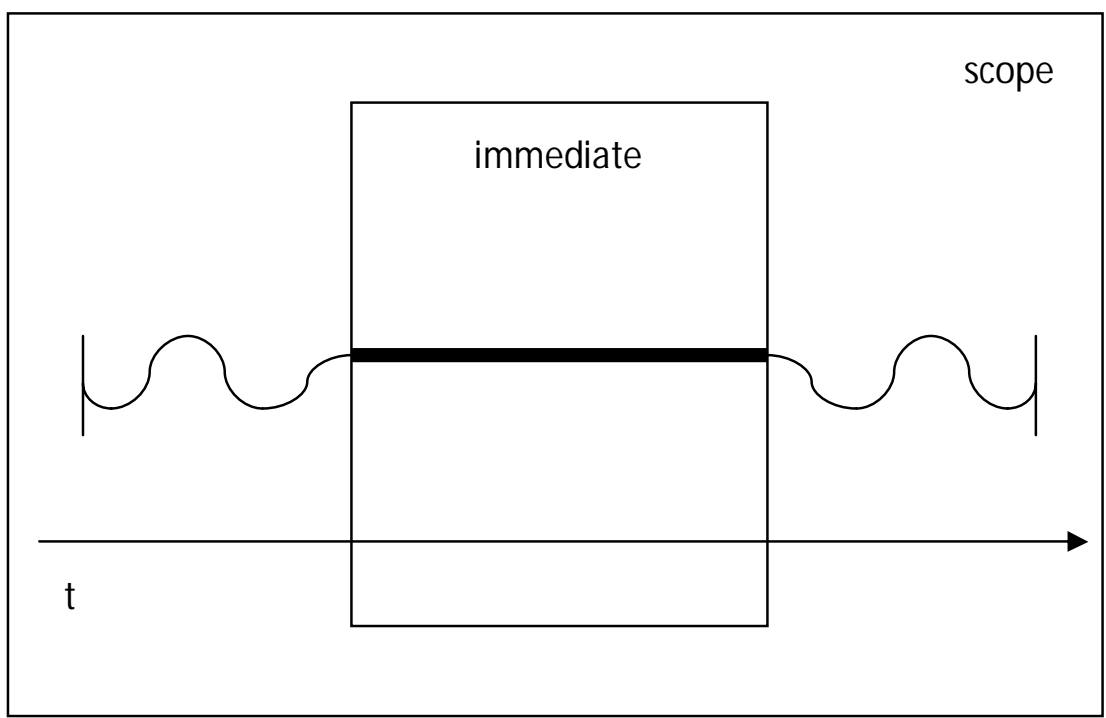

Figure 5 Semantics of -ing (2) (Langacker, 2002, p. 92)

For reasons of economy, a detailed CG analysis of the English present tense cannot be offered here (see Langacker, 1991). What will suffice for the present purposes is the prototypical value CG ascribes to what are usually treated as present tense morphemes (zero and -s), which is to indicate "the occurrence of a full instantiation of the profiled process that precisely coincides with the time of speaking" (Langacker, 1991, p. 250). This prototypical meaning basically conforms to a commonsense understanding of the present tense, which is probably also accepted by traditional accounts, although rather tacitly.

At this point, it is clear how CG explains the fact that the progressive may only be used with perfective verbs, and not with imperfectives. What remains to be clarified in CG terms is the use of both verb types with the English present tense and the progressive aspect to refer to situations, or processes, happening or existing at speech time. This may be done by answering three questions concerning the use of these elements. The first two answers essentially report the analysis of Langacker (1991, pp. 250-252).

The first question is why the nonprogressive present tense, when referring to something unfolding at the moment of speaking, may be freely used with imperfectives, but not with the majority of perfectives. It follows from the CG definition of the present tense that the immediate scope of a present tense clause, which delimits its profile, is coextensive with the time of the 
speech event. This means that its duration is quite short. However, it is possible to use a present tense imperfective verb such as know in He knows it no matter how long the process is in objective reality. In CG this is seen as resulting from the inherent contractibility, brought about by the lack of bounding, and from the effective homogeneity of imperfective processes, whose component relations coincident with the (usually short) time of speaking count as a full instantiation of the process. The incompatibility of the present tense with the majority of perfectives follows from the fact that most of them profile, just as imperfectives, processes longer than speech time. Contrary to imperfectives, however, this conflict between the present tense and perfective processes cannot be resolved, because the latter do not have the features of contractibility and effective homogeneity. For this reason, the portion of the process coextensive with the speech event, which as a whole is longer than this event, does not count as a full instantiation of the process. For this to happen, the whole bounded perfective process, including its endpoints, would have to be viewed as simultaneous with the time of speaking, which is sometimes possible, as explained in the following paragraph.

The second question is why it is possible to use the English nonprogressive present tense with certain perfective verbs. According to CG, the so-called performative verbs such as promise and order, profiling the speech event itself, for example the act of promising in I promise to be home on time, satisfy the requirement that the designated process, including its endpoints, be simultaneous with the speech event. Clearly, the speech act of promising is exactly as long as the time required to utter it.

The third question is why exactly most perfective verbs require the progressive when used in the present tense. The answer should be quite obvious by now. It has been shown that, in contrast to perfectives, imperfectives may be freely used with the simple present. It has also been shown that the progressive imperfectivizes an otherwise perfective process. The conclusion that offers itself is that perfectives, when combined with the progressive whereby they become imperfective, are compatible with the present tense.

\section{Rationale for Employing CG Descriptions in Grammar Teaching}

This section presents the reasons for which CG might be a desirable source of grammatical descriptions to be used in instruction. Table 1 features a comparison of CG and traditional descriptions, with the criteria of comparison selected so as to reveal certain potential advantages of CG over traditional accounts. The table includes pedagogically important features of CG and their exemplification as well as corresponding information on traditional practi- 
cal/pedagogical grammars. Whenever possible, the exemplification is based on the descriptions offered earlier in the paper.

Table 1 Comparison of CG and traditional grammars as sources of pedagogical rules

\begin{tabular}{|c|c|c|c|}
\hline $\begin{array}{l}\text { CG as a basis of peda- } \\
\text { gogical rules }\end{array}$ & CG examples & $\begin{array}{l}\text { Traditional pedagogical } \\
\text { rules }\end{array}$ & $\begin{array}{l}\text { Traditional grammar } \\
\text { examples }\end{array}$ \\
\hline $\begin{array}{l}\text { M eaningfulness of all } \\
\text { grammatical elements } \\
\text { and highly detailed } \\
\text { analyses of their mean- } \\
\text { ings }\end{array}$ & $\begin{array}{l}\text { Of is meaningful; the } \\
\text { analysis of the semantic } \\
\text { contributions of the } \\
\text { components of the Eng- } \\
\text { lish progressive: be, -ing, } \\
\text { and of the English pre-- } \\
\text { sent tense }\end{array}$ & $\begin{array}{l}\text { Not all grammatical } \\
\text { elements are meaning- } \\
\text { ful and analyses of } \\
\text { their meanings not as } \\
\text { detailed as in CG }\end{array}$ & $\begin{array}{l}\text { No meaning ascribed to } \\
\text { of; no semantic analysis } \\
\text { of the components of } \\
\text { the English progressive } \\
\text { and no precise seman- } \\
\text { tic value of the English } \\
\text { present tense }\end{array}$ \\
\hline
\end{tabular}

Grammatical meaning is conceptualization, existence of different construals

Discourse and other pragmatic factors often included in the meaning of grammatical features

Grammar is motivated

Little/ no vagueness and imprecision of description

No contradictions between different rules/subrules

Different conceptualizations and construals of perfective and imperfective verbs, even in the case of seemingly stative verbs such as like

The specification of the discourse functions of the $-s$ and of possessives Discourse and other pragmatic factors not/rarely included in the meaning of grammatical features

The use of the nonprogressive present tense with performatives clearly explained by the semantics of these elements

Grammar is often arbitrary grammatical items specified

(n)




\begin{tabular}{|c|c|c|c|}
\hline & & & $\begin{array}{l}\text { as promise and refuse, } \\
\text { which denote appar- } \\
\text { ently dynamic situa- } \\
\text { tions, and the rule } \\
\text { stating that the } \\
\text { nonprogressive present } \\
\text { is used to refer to } \\
\text { thoughts, feelings, } \\
\text { states and permanent } \\
\text { facts }\end{array}$ \\
\hline $\begin{array}{l}\text { Frequent use of pictorial } \\
\text { illustrations of meaning }\end{array}$ & $\begin{array}{l}\text { Figures accompanying } \\
\text { the description of per- } \\
\text { fective and imperfective } \\
\text { verbs and the progres- } \\
\text { sive in English }\end{array}$ & $\begin{array}{l}\text { Infrequent use of } \\
\text { pictorial illustrations of } \\
\text { meaning }\end{array}$ & \\
\hline
\end{tabular}

As can be seen from the table, the first difference between the traditional and CG approaches to grammatical description is the insistence of the latter on the meaningfulness of grammar and its provision of detailed analyses of grammatical meanings, neither of which is shared by the former. One example is the elucidation by CG of the meaning of the English preposition of, which is considered as semantically empty in traditional accounts (for details see Bielak, 2007). Another example is the meticulous breakdown of the meaning of the English progressive (see above), which is traditionally analyzed in much cruder semantic grain. Conceptualization and pragmatic factors, which are discussed next, are two special facets of the meaningfulness of grammar.

Another difference between the two modes of description is that traditional treatments do not elucidate the conceptual import of grammatical phenomena, while it is the essence of CG descriptions that they do. The consequence of the absence from traditional accounts of the focus on conceptualization is their employment of often lengthy lists of 'functions,' 'meanings' or 'uses' of grammatical features, which are in turn characterized by a high degree of arbitrariness, an issue to be presently discussed. An example of such a list is the one already presented, which includes the 'exceptional' use of verbs such as like when combined with the progressive to refer to a situation of short duration. In CG, however, where the description of the conceptual content of grammatical items including the way it is construed is the norm, such lists of unrelated meanings or uses are not encountered. To explain the behavior of verbs such as like, CG simply evokes two ways of construing the same conceptual content, which are the construals associated with imperfective and perfective verbs.

The next difference between traditional and CG accounts of grammatical meanings is that the former are generally devoid of references to discourse 
functions, while the latter often include such references. As this difference cannot be demonstrated in relation to the descriptions offered earlier in the paper and it is not relevant to the pedagogic interventions used in the present study, it will not be further discussed.?

Yet another difference is that traditional rules seem to be arbitrary (cf. Chalker, 1994, p. 31) in the sense that no general principles uniting the apparently unrelated rules or uses concerning a grammatical item are given (cf. e.g., Littlemore, 2009, p. 61; Tyler \& Evans, 2004, p. 257), while CG analyses offer such overarching principles (cf. e.g., Tyler and Evans 2004, p. 258). For example, the traditional rule that the nonprogressive present is used with verbs such as promise and refuse seems to be arbitrary as there is nothing in the traditional account that relates it to the overall rule that this tense/aspect pairing is used with stative verbs. By contrast, the CG description of the same language facts follows clearly from the CG definition of the (nonprogressive) present tense, which admits both imperfectives (stative verbs) as well as these perfectives which profile actions coextensive with the time of speaking.

A further difference is that traditional descriptions are often highly vague and imprecise, while CG ones are not (cf. Turewicz, 2000, pp. 27-32). An example of vagueness is found in the set of traditional rules included above, where in Rule 3a. no explanation is offered as to why the example verb think refers to an action in one sentence and to a state in another. In contrast to traditional accounts, among the CG descriptions offered above no such descriptive vagueness nor imprecision is to be found.

The next difference can also be stated in terms of a feature characterizing traditional descriptions, but not CG ones. This is the fact that when the rules concerning a particular grammatical area are considered in total, some contradictions among them become apparent. For instance, according to Rule 4, the nonprogressive present is used with such verbs as promise and refuse, and, given the fact that the actions they denote may be considered dynamic, it contradicts Rule 3 , which states that the nonprogressive present tense refers to states. The CG description of the same grammatical area is devoid of such contradictions.

The last difference is the fact that CG makes extensive use of pictorial and diagrammatic representations of the semantics of grammatical features, while traditional accounts do not. This is demonstrated by the preceding section, where the subsection with CG descriptions abounds in figures illustrating grammatical meanings, while the traditional description section does not contain any such illustrations.

\footnotetext{
${ }^{7}$ For details of the examples cited in this part of Table 1 see Bielak (2007).
} 
At this point, let us enumerate the possible learner benefits that the above features of CG descriptions may bring about, in contrast to, or to an extent greater than, traditional ones. All of these benefits but the first one are suggested by Boers and Lindstromberg (2006). First, the lack of arbitrariness and the lower number of rules to be assimilated it entails may result in the rules constituting a lesser burden on learners' memory. Second, the detailed analyses of grammatical meaning are supposed to result in deep processing and understanding of grammar and heightened language awareness. Third, the meaningfulness of grammar and the use of pictorial representations may boost retention. Finally, the lack or low degree of arbitrariness, vagueness and contradictoriness are expected to result in positive affect. It should be remembered that it is also possible to list some features of CG descriptions which may be potential drawbacks when CG is applied in pedagogy. Among them is the weak motivation behind certain meanings/uses (Boers \& Lindstromberg, 2006, pp. 320-321), the novel terminology of the theory and the high degree of abstractness of some of its concepts.

\section{The Study}

As already mentioned, the study set out to explore the effectiveness of form-focused instruction based on CG and compare its effects with those of teaching based on traditional pedagogical descriptions. Specifically, it sought to address the following research questions:

- Is grammar teaching based on CG descriptions of grammatical elements effective?

- Is there a difference between the effects of CG-inspired form-focused instruction and the same kind of instruction based on traditional pedagogical descriptions in both the short and the long run?

The study reported here took the form of a quasi-experiment with a pretest-posttest design. The assessment procedure consisted of a pretest, given one week prior to the treatment, an immediate posttest (Posttest 1), given one week after the treatment, and a delayed posttest (Posttest 2), administered three weeks after the treatment, as specified in Table 2 . The data collected were subjected to quantitative analysis. It should also be mentioned that the study had been piloted, including its tests and instructional treatments.

The study involved exposing two experimental groups to two different instructional treatments aimed at improving their control and use of the target forms. The treatment, which employed instructional materials devised by the present authors and lasted approximately $80 \mathrm{~min}$, was based on traditional pedagogical grammars in one experimental group, and on CG descriptions in the 
other. Hence, the two kinds of treatment were called traditional and cognitive, respectively. Besides, a control group was included in the design of the study.

Table 2 Research schedule

\begin{tabular}{ll}
\hline Week & Procedure \\
\hline 1 & Pretest \\
2 & Treatment $(70-85 \mathrm{~min})$ \\
3 & Posttest 1 \\
4 & Posttest 2 \\
\hline
\end{tabular}

\section{Participants}

The participants of the study were 50 Polish grade one and two senior high school students, including 15 males and 35 females. On average, they had had 5.18 years of instruction in English, with considerable intra-group variation in this respect, and also with respect to the number of hours of instruction they had received, which makes the participants a typical mixed-level group. The participants were much more uniform when it comes to such factors as extracurricular instruction and out-of-school exposure, which were generally insignificant, and also as far as their motivation is concerned, which was instrumental in an overwhelming number of cases. The participants belonged to four intact classes, which constituted three groups for the purposes of the study. The first was labeled the Traditional Group (TRAD, $n=15$ ), as it later received the traditional treatment; the second one was dubbed the Cognitive Group (COG, $n=21$ ), as its treatment was cognitive; and the third one was designated as the Control Group (CTRL, $n=14$ ).

\section{Target Forms}

The decision to focus on the meanings and use of the English present tense and progressive aspect, as well as stative (imperfective) and dynamic (perfective) verbs, was motivated by a host of practical, pedagogic and theoretical factors. First, for reasons of practical nature related to the institutional setting of the quasi-experiment, the target forms had to be relatively simple and amenable to instruction in one and a half hours. Therefore, the decision to teach the progressive and nonprogressive present tense was made, as these grammatical elements are relatively simple, at least when compared with other elements of the English tense/aspect system. The choice of the target features was further restricted by focusing on the present tense with or without the progressive to refer to situations existing or happening at speech time. 
Additionally, certain verb types had to be ignored as well. ${ }^{8}$ Although such decisions prevented the presentation of the grammatical material in greater complexity, they enabled the design of time-compact instructional treatments.

In addition, pedagogical and theoretical considerations also influenced the choice of the target forms, which were supposed to constitute a challenge to the participants in terms of both explicit and implicit knowledge. They are too numerous to be discussed here in detail (for a more extensive discussion see Bielak \& Pawlak, in press); it will suffice to say that they are related to such issues as the Polish and English contrastive analysis, developmental sequences, the lack of transparent form-meaning-function relationships in some of the target features, their low salience in perception, and their semantic redundancy. It should be added that the semantic aspects of the target structures were at the centre of attention in the study, with form focused upon only incidentally in the feedback provided.

\section{Instructional Treatment}

The two experimental groups received their treatment during regularly scheduled school classes. The instructor delivering the treatment was one of the present authors. Although the two kinds of treatment were different in essence, they employed exactly the same language data and were otherwise as similar as possible. All the metalinguistic comments and other instructions were in Polish, which was necessitated by the low level of advancement of numerous participants. The duration of the treatment was originally intended to be the same in TRAD and COG. However, the pilot study revealed that the cognitive treatment, which required a more detailed discussion of the semantics of the target forms, had to be approximately 15 min longer than the 70 -

\footnotetext{
${ }^{8}$ For instance, verbs which are best categorized as intermediate between stative and dynamic, such as the so-called stance verbs (e.g., sit, live) (cf. Quirk et al. 1985, pp. 205ff), verbs of bodily sensation (e.g., hurt, tickle) (cf. Quirk et al. 1985, p. 203) and the verb look were not covered by the instructional treatment as the exposition of some of their idiosyncratic features would have unduly stretched the treatment. In addition, even the kinds of dynamic verbs focused on were restricted in certain ways. For an influential taxonomy of dynamic verbs (and of lexical aspect) used in this footnote see Vendler (1957). The treatment and tests excluded activities (atelic verbs), and they only included achievements and accomplishments (telic verbs), both of which have a more clearly defined beginning and end in comparison with activities. This was done because achievements and accomplishments are easier to account for with the use of the boundedness/unboundedness distinction used in the cognitive treatment. Had the instruction and the tests also included activities, the treatment, and especially its cognitive version, would have had to be extended to accommodate these less prototypical dynamic/perfective verbs.
} 
min traditional treatment. Instruction in both groups was aided by the use of two different handouts and Power Point presentations. Because of its novelty, the following presentation of the cognitive treatment is much more detailed than that of the traditional treatment.

A combination of learner performance and feedback instructional options (cf. Ellis, 1997) was used in the two versions of the treatment. First, feature-focused, mostly inductive techniques were employed whose primary target was the participants' explicit knowledge. In the case of TRAD, its purpose was teaching the participants certain of the traditional rules presented above. They may be summarized as follows:

- When we talk about a situation happening or existing at the time of speaking, we use the present simple with stative verbs, which refer to states (e.g., thoughts and feelings, nothing is changing in a state); and we use the present continuous with dynamic verbs, which refer to actions (something is happening, something is changing in actions) (see Rules 1,2 and 3 above).

- Some verbs have different meanings in the sense that a given verb form sometimes refers to a state, and sometimes to an action. Such verbs may be called stative-dynamic verbs. When they refer to a state, the present simple is used when we talk about a situation existing at speech time, and if they refer to an action, the present continuous is used (see Rule 5).

- When we talk about a situation taking place at speech time and we use a verb referring to an action consisting in speaking, the present simple is used (see Rule 4).

The first part of the treatment offered to COG intended to teach the participants the major CG principles concerning the target features. What is offered here is a concise summary of this treatment (for a full account see Bielak \& Pawlak, in press). The representations in Figures 7 and 8 were used to teach the participants the CG view of the present tense, according to which it is used to mark a given situation as coextensive with the time of speaking. In the figures, the short time it takes to utter the Polish example sentence (Pol. zdanie) Siedzę na krześle 'I am sitting on a chair,' approximately 1-2 s, exemplifies the time reference of the present tense. Figure 8 demonstrates that this time is so short that it may be likened to a keyhole. ${ }^{9}$

${ }^{9}$ The keyhole idea was inspired by a technique proposed by Niemeier (2005). 


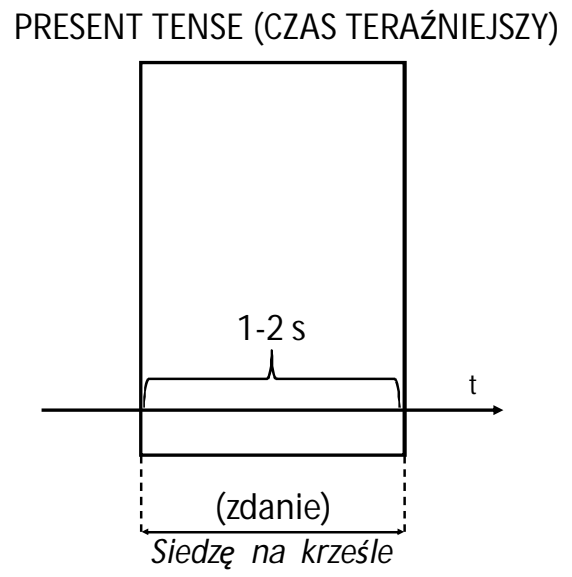

Figure 7 Cognitive treatment: the present tense

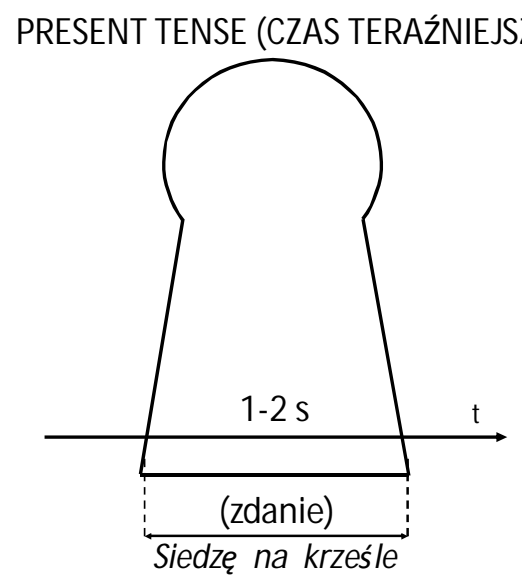

Figure 8 Cognitive treatment: the present tense as a keyhole

The next part of the treatment intended to confer to the participants, in a pedagogy-friendly manner, the CG view of imperfective processes as homogeneous and inherently contractible/ expansible. Towards this aim, a series of pictures similar to and including the ones in Figures 9, 10 and 11 were used, in which the meaning of the verb trust in the sentence Jerry trusted his girlfriend is portrayed. Figure 9 shows that, if it is assumed that the trusting started on 1 January and terminated on 31 December, the sentence may be used to refer to a series of relations between these points in time consisting in Jerry holding certain favorable beliefs about his 
girlfriend's worth, goodness or reliability. ${ }^{10}$ However, the other two figures show that the same sentence, and generally verbs such as trust, may be used to refer not only to the whole length of the situation, but also to any subpart, which, due to its restricted extension, may be likened to what may be perceived through a keyhole.

\section{TRUST}

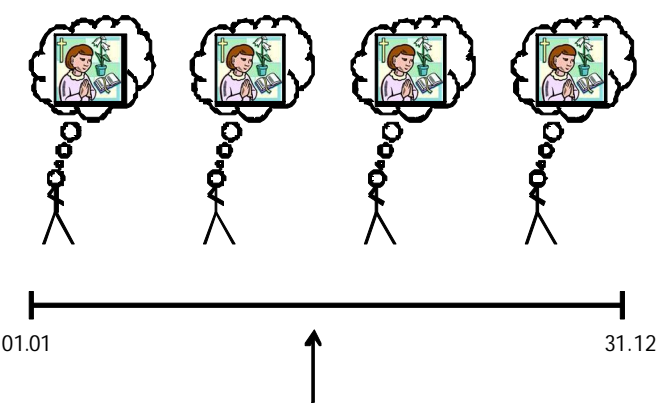

Jerry trusted his girlfriend.

Figure 9 Cognitive treatment: the verb trust (1)

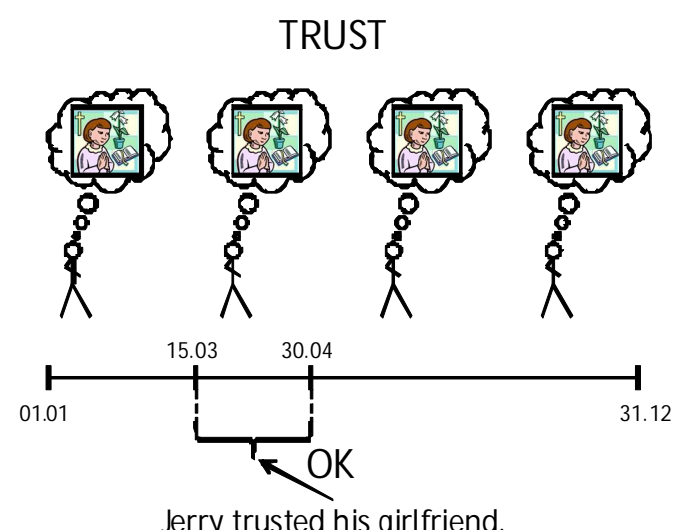

Figure 10 Cognitive treatment: the verb trust (2)

\footnotetext{
${ }^{10}$ In the figure, this general belief in the girlfriend's overall integrity is pictorially represented as a belief in her piousness, which is just an example which might be easily replaced with many others, but was selected since it was quite easy to represent in pictorial form.
} 


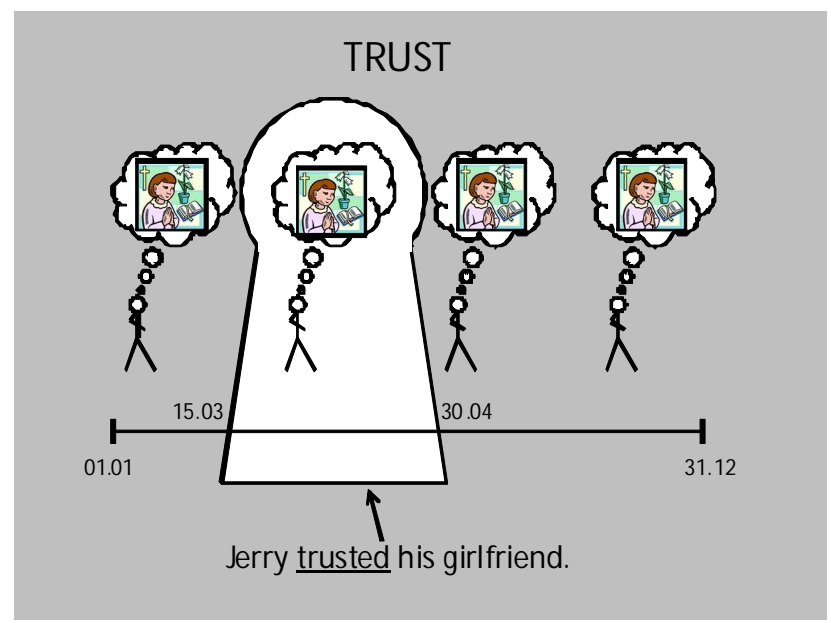

Figure 11 Cognitive treatment: the verb trust and the keyhole

Next, the participants were made aware of the view that imperfective (stative) processes are inherently unbounded in their temporal scope, which makes them compatible with the nonprogressive present tense. The representation in Figure 12 was used to highlight the fact that the endpoints of the process designated by trust are not important in the sense that there is no major change between the beginning of the situation and its end. This explains why dotting, rather than vertical lines, marks the endpoints of the timeline representing the process. At this point the participants were offered the following pedagogical rule:

- Stative verbs may be used in the simple present because their endpoints are not important/relevant (the verbs do not describe change), so we can view their situations through the (small/short) keyhole of the present tense.

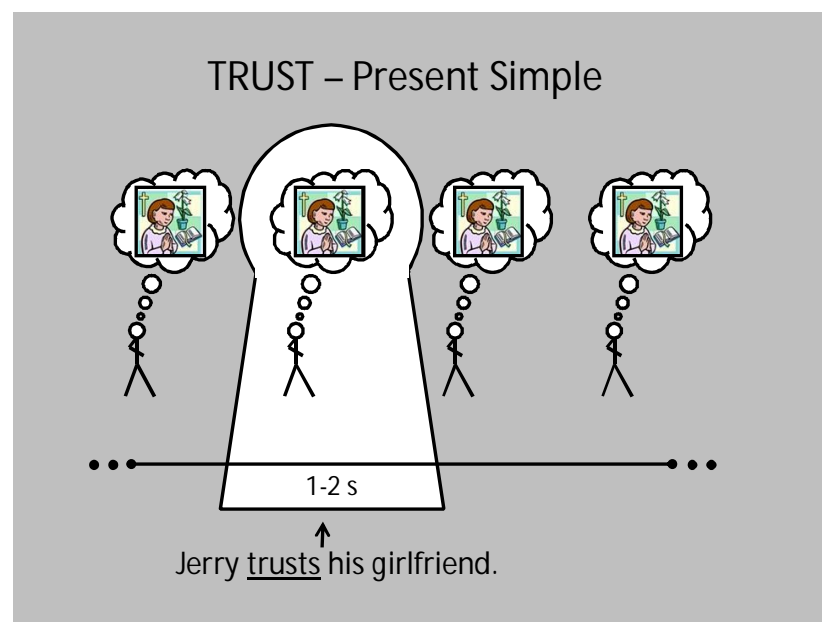

Figure 12 Cognitive treatment: the verb trust in the present simple 
Subsequently, the participants focused on the CG view of perfective processes as heterogeneous and not inherently contractible/expansible. To achieve this, a series of pictures was used, including the ones in Figures 13, 14 and 15 , which render the meaning of the verb build in the sentence Jerry built a castle, with the assumption that the action took place between 8:00 and 12:00. Figures 14 and 15 demonstrate that it is not possible to refer to any subpart of the whole process of building the castle expressed by this sentence by using the sentence itself. Figure 15 conveys this conclusion with the additional conceptualization of the shorter time span as a keyhole.

\section{BUID}

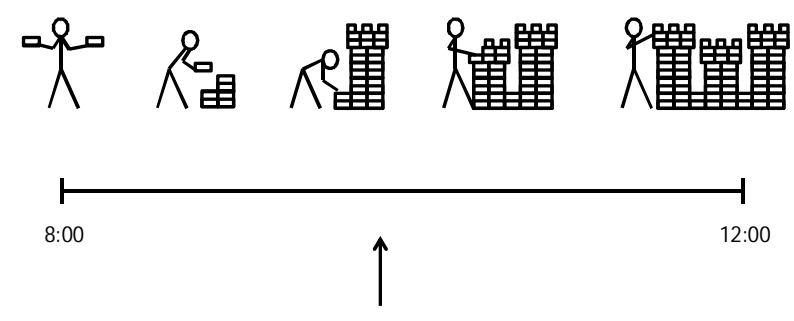

Jerry built a castle.

Figure 13 Cognitive treatment: the verb build (1)

\section{BUILD}

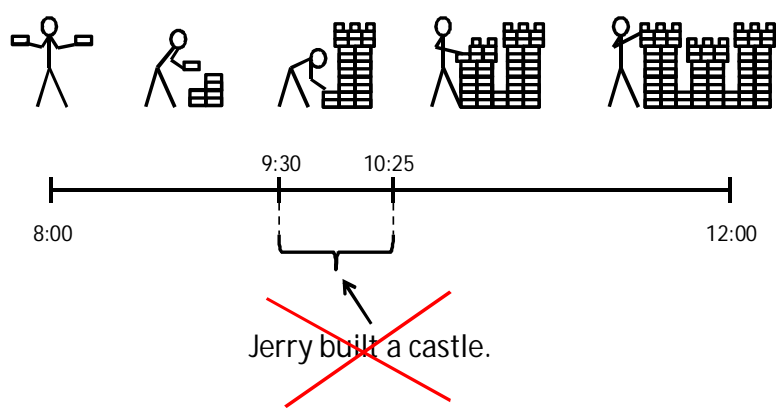

Figure 14 Cognitive treatment: the verb build (2) 


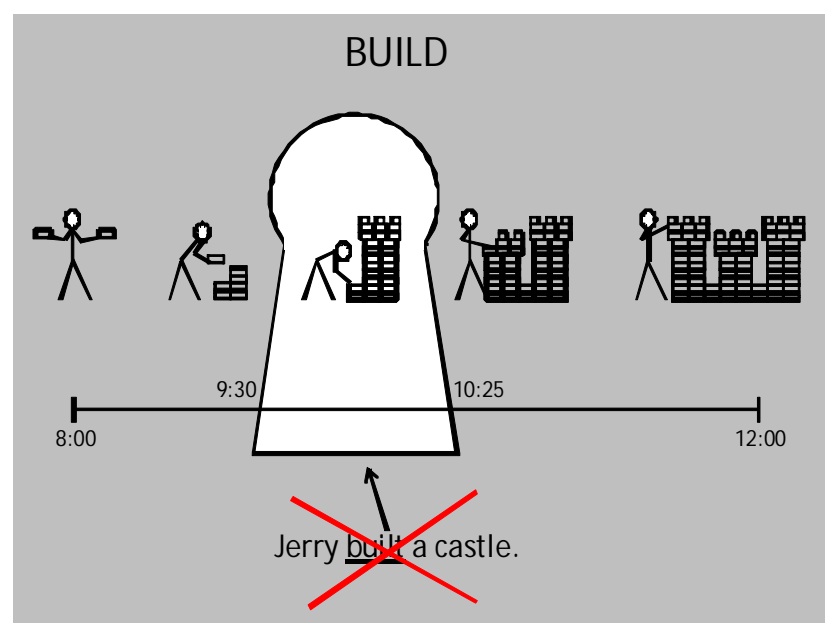

Figure 15 Cognitive treatment: the verb build and the keyhole

Next, the treatment focused on the fact that perfective (dynamic) processes are inherently bounded in their temporal scopes, which makes them incompatible with the nonprogressive present. The representation in Figure 16 underlined the CG assumption that the endpoints of the process symbolized by build and by other perfectives are important in the sense that there is some significant change between the beginning and the end of the situation; at the beginning the castle did not exist, and at the end of the process a complete castle was in existence. This is why the timeline for this verb in Figure 16 begins and ends with vertical lines highlighting the importance of the endpoints between which there is a qualitative difference. At this point the participants were offered the following rule:

- Dynamic verbs cannot be used in the simple present, because their endpoints are important/ relevant (these verbs describe a change between these endpoints), so we cannot view their situations through the keyhole of the present tense since the endpoints are outside of it. 


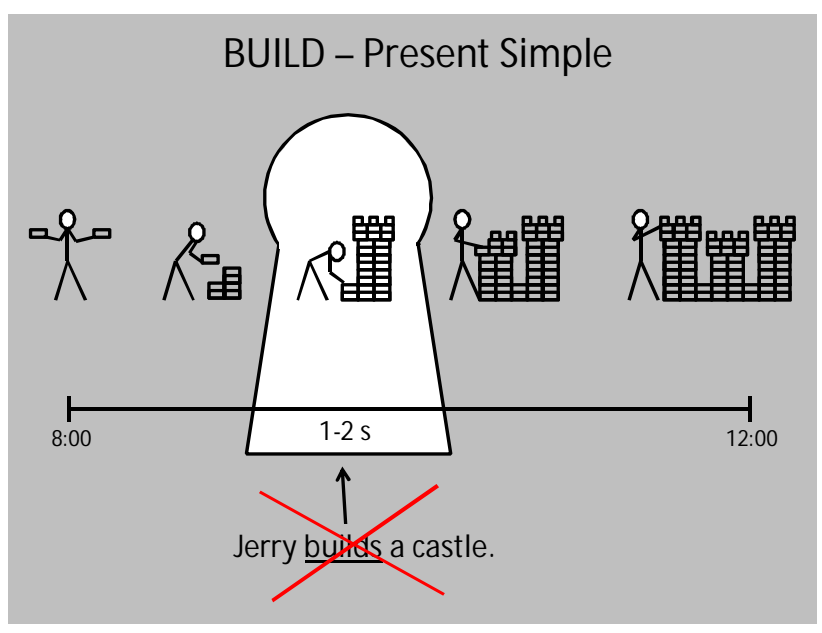

Figure 16 Cognitive treatment: the incompatibility of the verb build with the present simple

Next, the imperfectivizing function of the progressive aspect and its interaction with the present tense and lexical aspect were focused on. This was done with the help of the representations in Figures 17 and 18, which show that when the present progressive is used rather than the present simple with verbs such as build, the endpoints of the process cease to be important, and we are not interested in the change that occurs between them. At this point the participants were offered the following pedagogic formulation:

- Dynamic verbs may be used in the present continuous, because in this tense their endpoints are not important/relevant, so we may view their situations through the keyhole (of the present tense).

\section{BUILD}

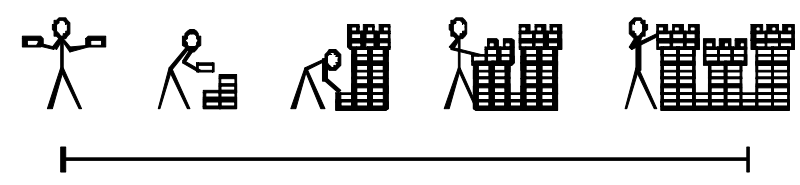

BUILD - Present Continuous
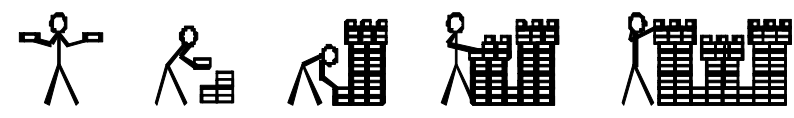

Figure 17 Cognitive treatment: the verb build with the nonprogressive and progressive aspect 


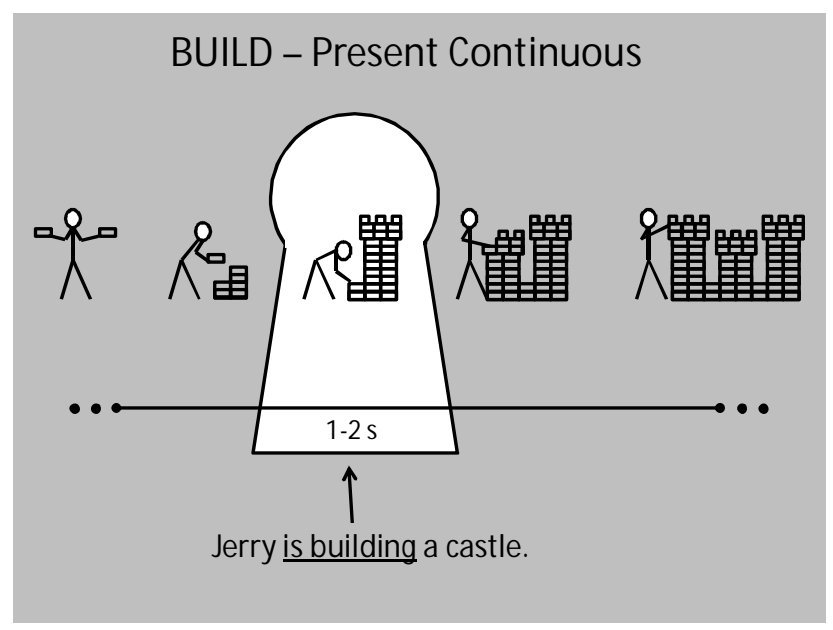

Figure 18 Cognitive treatment: the verb build in the present progressive

Finally, the participants were exposed to the CG description of the compatibility of the performative verbs with the nonprogressive present tense with the help of the illustration in Figure 19. They were then offered the following principle:

- When reference is made to the time of speaking, verbs referring to actions which consist in speaking are used in the present simple because these actions are as long as the time it takes to utter one sentence, so they are exactly as small (short) as the keyhole of the present tense.

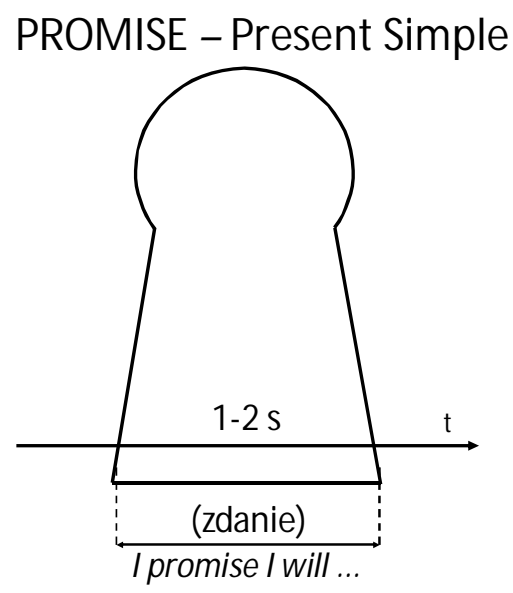

Figure 19 Cognitive treatment: the verb promise in the present simple 
The second part of instructional treatment in both experimental groups was in the form of three text manipulation tasks, which had the same form as the three tasks in the test, which is in turn described in more detail in the subsequent section. It will suffice to note here that their function was creating an opportunity for the participants to practice the target grammar. The activities were monitored by the instructor, who offered some overt feedback in the form of metalinguistic remarks, repetition, corrective recasts and focus on errors. Obviously, the feedback in the two kinds of treatment was different, as it reflected the two sorts of descriptions used.

\section{Data Collection and Analysis}

The testing instruments which provided the data in the whole project evaluated both controlled and spontaneous use of the target forms. The present paper concentrates only on the measure of mostly explicit knowledge, which took the form of a written discrete-item grammar test consisting of three parts. The first was a receptive knowledge selected response test in which the participants had to choose between a present simple and a present continuous verb phrase as part of a sentence or a longer exchange. The other two parts were productive knowledge constrained constructed response tasks. The first of these required the provision of the correct form of the base form of the verb given in brackets, again as part of a sentence or a longer exchange. In the next part, the participants read a sentence or a longer exchange written in Polish and then completed its English translation, which contained a gap. A verb phrase was always required to complete it, and, to ensure the use of the types of verbs which were targeted by the treatment, the base forms were also provided. The test included an English-Polish glossary and was administered within the time limit of 20 min by one of the present authors.

Because the split-block procedure was employed to ensure the same levels of difficulty of the pretest and the two posttests for each group, three versions of the test were designed (Tests A, B and C). Each group was divided into three subgroups which can be referred to as COG 1, COG 2, COG 3, TRAD 1, TRAD 2, and so forth. For the pretest, COG 1, TRAD 1 and CTRL 1 took Test A; COG 2, TRAD 2 and CTRL 2 took Test B; while COG 3, TRAD 3 and CTRL 3 took Test $C$. On each subsequent test the versions $A, B$ and $C$ were shuffled so that everybody took a test he or she had not taken before.

The maximum score was 72 points, as each of the three components included 12 items, each of which was worth maximally 2 points. In the binarychoice part, 2 points were awarded for the right response, and no points otherwise. For the remaining components, partial-credit scoring was used. Specifical- 
ly, 2 points were awarded if the supplied verb phrase was both formally correct and appropriate, even if some minor spelling mistakes were present. One point was given if the form of the verb phrase was inaccurate in some way (e.g., if there was a problem with the auxiliary, as in she don't weigh), but it was still clear which tense/aspect pairing the test taker had meant and if that was the right choice. No point was given if tense or aspect had been wrongly chosen, or if the form of the verb phrase was entirely incorrect, making it impossible to tell which tense/aspect pairing had been intended. Obviously, if no answer was provided, no points were awarded, either. Quantitative analysis involved computing the means and standard deviations for each of the three groups on the three tests as well as conducting one-way and repeated measures analyses of variance (ANOVAs) together with the requisite post host tests (Bonferroni, or Games-Howell if variances were not equal). The tests were conducted using the Statistical Package for the Social Sciences, version 19 for Windows.

\section{Results and Discussion}

A one-way ANOVA yielded no main effect for group $(F(2,47)=1.01, p=.37)$ on the pretest (see Table 3 ), and it was therefore concluded that any inter-group differences in subsequent analyses were not due to prior differences among the groups. The results of this test also supported the assumption that that original between-group differences were insignificant and therefore not responsible for differential performance the groups might display on subsequent tests.

Table 3 shows the means and standard deviations for the three groups on the tests, which measured accuracy and appropriateness in the use of the relevant tense/aspect pairings over three testing sessions. The means for these tests of mostly explicit knowledge are also plotted in Figure 20 for easier inter-group comparisons. These data reveal that all the groups improved from the pretest to Posttest 1, although the scores of the two experimental groups rose much more sharply than those of CTRL; COG improved by 7.26 points, TRAD by 11.14 points, while CTRL by mere 3 points. While the improvement of the experimental groups did not come as a surprise, CTRL's progress was unexpected and should be probably attributed to the practice effect. CTRL's performance on Posttest 2 was very similar to that of TRAD in the sense that both deteriorated minimally, TRAD by 0.47 of a point and CTRL by 0.07 of a point, from Posttest 1 . This means that the earlier moderate gain of CTRL and the more pronounced gain of TRAD were basically maintained on Posttest 2 . This is different from the gains of $C O G$, which were not just maintained but kept increasing from Posttest 1 to Posttest 2 to yield an improvement of 4.6 points. In the long run, between the first and the last test, CTRL improved just by 2.93 
points, while the gains of TRAD and COG were much greater and quite similar to each other, 10.67 and 11.86 points respectively.

Table 3 M eans and standard deviations for all groups

\begin{tabular}{lllllll}
\cline { 2 - 6 } & Groups & & & & \\
\cline { 2 - 7 } & $\begin{array}{l}\text { COG } \\
(n=21)\end{array}$ & & $\begin{array}{l}\text { TRAD } \\
(n=15)\end{array}$ & & $\begin{array}{l}\text { CTRL } \\
(n=14)\end{array}$ & \\
\hline Test & $M$ & SD & $M$ & SD & M & SD \\
\hline Pretest & 30.80 & 11.36 & 26.86 & 4.01 & 28.57 & 5.69 \\
Posttest 1 & 38.06 & 15.81 & 38.00 & 13.65 & 31.57 & 9.71 \\
Posttest 2 & 42.66 & 15.10 & 37.53 & 13.29 & 31.50 & 7.30 \\
\hline
\end{tabular}

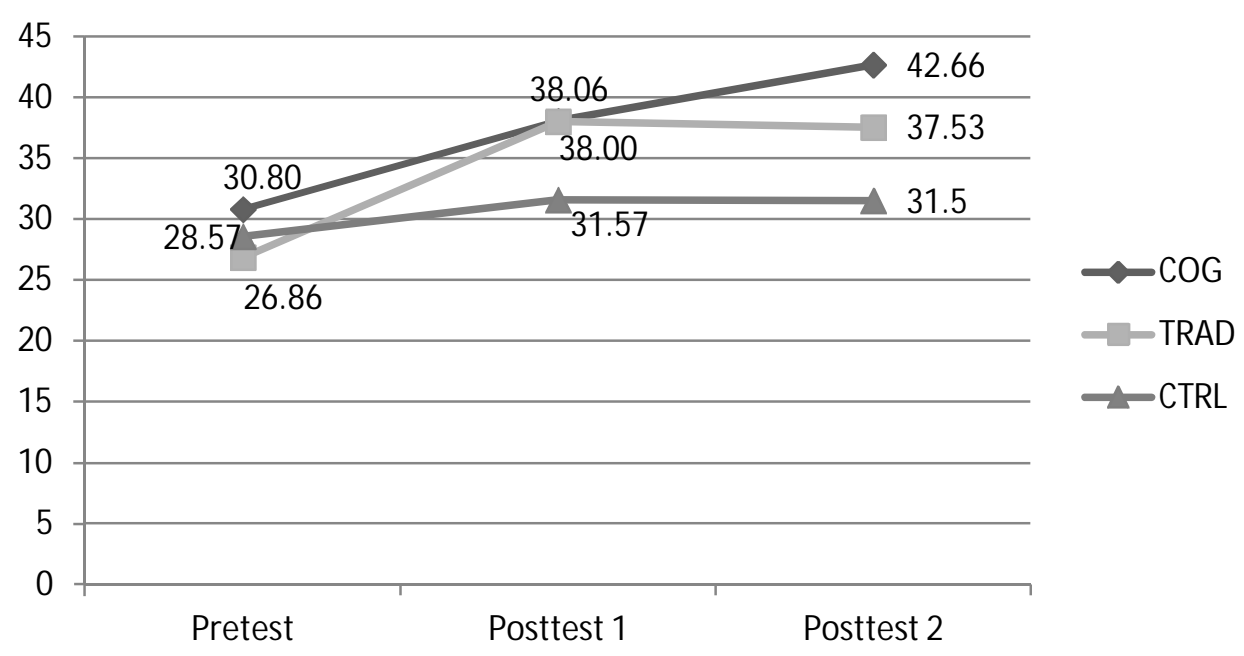

Figure 20 M eans for all groups

A repeated-measures ANOVA with one between-subjects variable (treatment group) and one within-subjects variable (time of test) was performed on the raw scores of the three groups using a general linear model, and its results are presented in Table 4 . This test yielded the interaction of treatment group with time of test of statistical significance, with $F(4,94)=$ 2.51, $p<.05, \eta_{p}^{2}=.09$, as well as significant main effects for time of test, with $F(2,94)=20.30, p<.001, \eta_{p}^{2}=.30$, and no significant main effects for treatment, with $F(2,47)=1.73, p=.18, \eta_{p}^{2}=.06$. These data mean that different treatment conditions resulted in significantly different scores at different times. It should be noted that the statistically significant results just reported 
are characterized by effect sizes which have to be regarded as either small (interaction of treatment group with time, $\eta_{p}^{2}=.09$ ) or large (time, $n_{p}^{2}=.30$ ) (cf. Cohen, 1988). The first of these is close to but below the conventionally established medium value, which means that the results have to be treated with caution; their overall significance, however, was taken to be nonnegligible. Given the fact that the pedagogic interventions took only up to 85 min, the significant result characterized by the effect size indicating that the interaction of time and treatment accounted for $9 \%$ of total variability in scores might still reveal a certain potential of the interventions. In the case of the second effect size, it meant that the time factor predicted $30 \%$ of the variance in test scores.

Table 4 Repeated measures ANOVA of the test scores across the two treatment and one control condition and the three testing sessions

\begin{tabular}{lllll}
\hline Source & df & $\mathrm{F}$ & $\mathrm{p}$ & $\eta_{\mathrm{p}}{ }^{2}$ \\
\hline Between subjects & & & & .06 \\
Group (COG, TRAD, CTRL) & 2 & 1.73 & .18 & \\
Error & 47 & & & \\
Within subjects & & & & .30 \\
Time & 2 & 20.30 & $<.001$ & .09 \\
Time x Group & 4 & 2.51 & $<.05$ & \\
Error & 94 & & & \\
\hline
\end{tabular}

To further explore the effects of the two kinds of treatment on the scores, a series of one-way ANOVAs and ANOVAs with repeated measures for different groups were run. A one-way ANOVA yielded a statistically significant result on Posttest 2: $F(2,47)=3.19, p=.05, \eta_{p}^{2}=.11$. Since the test of homogeneity of variances was statistically significant, a Games-Howell post hoc test was used, which revealed a significant between-group contrast involving COG and CTRL $(p<.05)$. It must have resulted from the fact that the steep pretestPosttest 1 progress registered by both TRAD and COG was continued from Posttest 1 to Posttest 2 only by COG (improvement by 4.6 points), while both CTRL and TRAD generally stayed at their Posttest 1 levels. Furthermore, ANOVAs with repeated measures found statistically significant discrepancies between different test scores of COG, with $F(2,40)=17.47, p<.001, \eta_{p}{ }^{2}=.46$, and of TRAD, with Greenhouse-Geisser correction $F(1.40,19.61)=8.01, p<$ $.01, \eta_{p}{ }^{2}=.36$. These results indicate that the time factor accounted for at least $36 \%$ of the total variance in scores, which is a definitely large effect size. A summary of these significant and near-significant results, as revealed by repeated-measures ANOVAs' pairwise comparisons, as well as of the sole statis- 
tically significant between-group difference, are provided in Table 5. It should also be added that there were no statistically significant differences over time in the scores of CTRL. What appears from these analyses is that both kinds of treatment had a pronounced effect on test scores, inducing their significant improvement from the pretest to Posttest 1 . This rising trend was maintained on the delayed posttest, as the differences between the pretest and Posttest 2 were also significant in the case of both experimental groups.

Table $\mathbf{5}$ Summary of statistically significant and near-significant between- and within-group differences

\begin{tabular}{lll} 
& Between-group & Within-group \\
\hline Pretest & & \\
Posttest 1 & COG $>$ CTRL & \\
Posttest 2 & & \\
COG & Pretest < Posttest $1^{*}$ \\
& Posttest $1<$ Posttest $2 \quad(p=.056$, \\
& near-significant difference $)$ \\
& Pretest < Posttest $2^{* * *}$ \\
TRAD & Pretest < Posttest $1^{* *}$ \\
& Pretest < $<$ Posttest 2** \\
CTRL & \\
\hline
\end{tabular}

$* p<.05$

$* * p<.01$

$* * * p<.001$

The results suggest that form-focused instruction based on CG may be at least moderately effective with respect to explicit grammatical knowledge. This follows from COG's significant improvement from the pretest to Posttest 1 , from the pretest to Posttest 2 , as well as from its nearly significant improvement from Posttest 1 to Posttest 2 . The same conclusion is supported by the statistically significant difference between the scores of COG and TRAD on Posttest 2. The effectiveness CG-based instruction is pronounced cautiously, because there were no statistically significant differences between COG and CTRL on the immediate posttest. It should be remembered, however, that the treatment received by COG was rather short for such a complex and inherently difficult area of English grammar as tense and aspect. It may also be concluded that the effects of CG-inspired teaching were durable, as not only were COG's immediate gains maintained, but they were actually improved from Posttest 1 to Posttest 2. When the effectiveness of teaching based on CG and that based on traditional descriptions are compared, the results provide no evidence of any major differences, as both kinds of treatment resulted in comparable 
gains in terms of the use of the target structures in controlled reception and production. It should be borne in mind, however, that similar gains were brought about by treatments of slightly different duration, with COG' treatment approximately 15 min longer.

Even though definitive answers may not be found, it is worth attempting to explain these results. The effectiveness of form-focused instruction based on CG and its durability may easily be explained by the general case for this kind of instruction presented earlier in the paper, as the CG descriptions drawn on in the cognitive treatment bore most of the pedagogically advantageous features discussed in that section. The favorable effects of instruction based on traditional descriptions and their durability are not particularly consonant with the potential disadvantages of this kind of teaching transpiring from the comparison with CG offered above. What may have outweighed the drawbacks of traditional descriptions is their relative simplicity, which may have been especially advantageous given the fact that the treatment was quite short.

The finding that the two instructional options may produce comparable effects may be somewhat surprising as the pedagogy-oriented comparison of the CG and traditional descriptions seemed to favor the CG ones. One possible explanation is that the cognitive treatment, which was quite complex and therefore probably more challenging to the participants, was not highly relevant to this particular group of learners, in contrast to the traditional treatment. The term relevant is used here in Swan's (1994) sense, for whom a rule is relevant to the extent to which it respond to the needs of particular learners. Given the fact that the participants were not a high-level group, the cognitive treatment may have been simply too complex and challenging to them, despite the fact that it relied on pedagogy-friendly, simplified renditions of the relevant CG descriptions. By contrast, the traditional treatment, which was relatively simple and with certain elements of which the participants may have been already familiar from earlier instruction, may not have posed a comparable challenge and might thus have been more relevant to their needs, especially in the case of those at lower levels of advancement.

Yet another explanation of basically the same effect of the two treatments has to do with the forms targeted. While the cognitive treatment made use of nuanced semantic analyses, in this particular case, due to the highly restricted focus of the treatment resulting from the practical considerations discussed earlier, there was no need to refer in it to pragmatic considerations. It is possible, however, that this is the area where CG has the most to contribute to form-focused instruction. If so, it is perhaps the case that grammatical features the description of which would be greatly facilitated by the inclusion 
of pragmatic information benefit most when subject to CG-inspired teaching, because such information rarely figures in traditional descriptions.

Another possible explanation of the comparable effects of the two kinds of treatment resembles the one proposed by Tyler et al. $(2010$, p. 46) to account for the moderate effects of teaching English modals with the help of CG that they reported. No advantage of CG-based teaching over traditional instruction may have been due to the fact that the treatment in COG was relatively short and restricted to selected aspects of a handful of grammatical features. It might be argued that had the treatment been longer, and had it covered a wider range of grammatical features, or even the same features, but in finer detail, its effects, assuming a parallel extension of the traditional treatment, might have been better than those of that treatment. This is supported by the fact that CG offers a highly comprehensive and unified view of language, where basically the same constructs are used to characterize multiple, often seemingly remote grammatical phenomena. It therefore seems plausible that CG teaching may achieve its full potential only if it is implemented over more extended periods and covers a wider range of features and their uses.

For instance, the notions of boundedness and unboundedness, which CG evokes to account for the difference between perfectives and imperfectives and the meaning of the progressive, are also at the foundation of the mass/count noun distinction in CG. Moreover, because of their association with the -ing form, these notions are also evoked in CG to describe all of its other uses, including for instance the choice between the present participle and the base form after verbs of perception or the use of the progressive with the past tense and modals. Considering the multitude of grammatical constructions in the teaching of which the notions of boundedness and unboundedness may be used suggests that if all of them were to be taught with the help of CG, this process might be greatly facilitated, as learners who once grasp the nature of the boundedness/unboundedness distinction may subsequently enjoy its benefits by simply applying it to a number of different areas of grammar. Traditional instruction, by contrast, would probably place heavier demands on learners by necessitating their assimilation of new, unrelated (arbitrary) analyses or rules pertaining to each of these different grammatical features and their uses.

\section{Conclusion}

The results of research reported in the paper endorse neither unqualified enthusiasm with respect to the employment of CG descriptions in grammar teaching nor their rejection as a possible alternative to traditional descriptions. It was concluded that CG-inspired instruction may be at least moderate- 
ly effective in terms of fostering the use of the target forms on the basis of mostly explicit knowledge, and its effects were found to be comparable to these achieved by employing traditional descriptions. It seems that these results should not discourage researchers from embarking on further exploration of the effectiveness of CG-based instruction. Quite to the contrary, since they offer some evidence that this kind of instruction may be effective, further research seems to be required to achieve a more comprehensive picture of the strengths and liabilities of this kind of teaching.

Before some directions for future research are outlined, the limitations of the present study should be considered. A major limitation dictated by important practical considerations was the relative shortness of the treatment, and it was responsible for some other limitations. First, the practice part of the treatment lacked a truly communicative component, which may be essential to maximize the effectiveness of explicit instruction. Second, the target forms and their uses were heavily restricted, which precluded any reference to pragmatic considerations. Another important limitation also related to time is that the cognitive treatment, due to its greater complexity, had to be somewhat longer than the traditional treatment, which should be borne in mind when considering the finding that both kinds of instruction resulted in comparable gains. It is after all possible that if the treatment in TRAD had been of exactly the same duration as that in COG, TRAD's results would have been much better than those of COG on Posttest 1, and equally good on Posttest 2 . All of these limitations should be eliminated in subsequent research to achieve a better picture of the effectiveness of the two kinds of teaching.

While considering the limitations of the study, let us also mention that given the fact that the participants had partially acquired the targeted features prior to the study, one cannot exclude the possibility that the latent knowledge they had in this area might have influenced their performance in subtle ways. This, however, is a woe that all researchers investigating the effects of formfocused instructions often have to face, and little can be done to eliminate it.

Some of the possible determinants of the results of the study might be manipulated in subsequent research. The first one is the considerable complexity of the cognitive treatment. Although it may seem that CG descriptions tend to be inherently complex, it also seems that there is some room for finetuning the pedagogical renditions of these descriptions which occurred in the cognitive treatment. After all, this treatment has to be considered as a pioneering attempt to translate CG descriptions of elements of English tense/aspect into pedagogically exploitable formulations. Also, the introduction of CG-based teaching earlier on in the educational process might be considered, which might also entail covering not just one or two points of gram- 
mar, but a whole range of them, which seems to be particularly fitting if the conceptual unity and comprehensiveness of CG are taken into account. This might in fact result in CG-based teaching being of the same duration as that of traditional instruction, because familiarizing learners with CG concepts in a gradual manner might not require as elaborate explanations as the ones used in the cognitive treatment used in the present study.

\section{Acknowledgements}

The authors wish to thank the anonymous reviewers of this paper for their insightful comments as well as encouragement, which they found extremely useful and motivating when preparing the final draft and which are bound to enhance their future research and its reporting. 
References

Achard, M. (2008). Teaching construal: Cognitive pedagogical grammar. In P. Robinson \& N. C. Ellis (Eds.), Handbook of cognitive linguistics and second language acquisition (pp. 432-455). New York: Routledge.

Bielak, J. (2007). Applying Cognitive Grammar in the classroom: Teaching English possessives. In M. Pawlak (Ed.), Exploring focus on form in language teaching [Special issue]. Studies in Pedagogy and Fine Arts, 7, 113-133.

Bielak, J., \& Pawlak, M. (in press). Applying Cognitive Grammar in the foreign language classroom: Teaching English tense and aspect. Heidelberg: Springer.

Boers, F., \& Lindstromberg, S. (2006). Cognitive linguistic applications in second or foreign language instruction: Rationale, proposals and evaluation. In G. Kristiansen, M. Achard, R. Dirven, \& F. J. Ruiz de Mendoza Ibáñez (Eds.), Cognitive linguistics: Current applications and future perspectives (pp. 305-355). Berlin: M outon de Gruyter.

Celce-M urcia, M., \& Larsen-Freeman, D. (1999). The grammar book: An EFL/ESL teacher's course (2nd ed.). Boston: Heinle \& Heinle.

Chalker, S. (1994). Pedagogical grammar: Principles and problems. In M. Bygate, A. Tonkyn, \& E. Williams (Eds.), Grammar and the language teacher (pp. 31-44). New York: Prentice Hall.

Cohen, J. (1988). Statistical power analysis for the behavioral sciences (2nd ed.). Hillsdale, NJ: Lawrence Erlbaum.

Eastwood, J. (1999). Oxford practice grammar (2nd ed.). Oxford: Oxford University Press.

Ellis, R. (1997). SLA research and language pedagogy. Oxford: Oxford University Press.

Huddleston, R., \& Pullum, G. K. (2002). The Cambridge grammar of the English language. Cambridge: Cambridge University Press.

Huong, N. T. (2005). Vietnamese learners mastering English articles (Doctoral dissertation, University of Groningen). Retrieved from http://dissertations. ub.rug.nl/FILES/faculties/ppsw/2005/h.n.thu/thesis.pdf

Król-Markefka, A. (2010). Metalinguistic knowledge and the accurate use of English articles: The effects of applying Cognitive Grammar in second language teaching (Unpublished doctoral dissertation). Jagiellonian University, Cracow.

Langacker, R. W. (1987). Foundations of cognitive grammar: Vol. 1. Theoretical prerequisites. Stanford: Stanford University Press.

Langacker, R. W. (1991). Foundations of cognitive grammar: Vol. 2. Descriptive applications. Stanford: Stanford University Press. 
Langacker, R. W. (2002). Concept, image, and symbol: The cognitive basis of grammar (2nd ed.). Berlin: Mouton de Gruyter.

Langacker, R. W. (2008). Cognitive grammar: A basic introduction. Oxford: Oxford University Press.

Littlemore, J. (2009). Applying cognitive linguistics to second language learning and teaching. Basingstoke: Palgrave M acmillan.

M ańczak-Wohlfeld, E., Niżegorodcew, A., \& Willim, E. (2007). A practical grammar of English (10th ed.). Warszawa: Wydawnictwo Naukowe PWN.

Niemeier, S. (2005). Boundedness/unboundedness: Blick durch das Schlüsselloch. Angewandte kognitive Linguistik für den Englischunterricht. Zeitschrift für Angewandte Linguistik, 43, 3-31.

Niemeier, S., \& Reif, M. (2008). Making progress simpler? Applying cognitive grammar to tense-aspect teaching in the German EFL classroom. In S. De Knop \& T. De Rycker (Eds.), Cognitive approaches to pedagogical gram$\operatorname{mar}$ (pp. 325-356). Berlin: Mouton de Gruyter.

Quirk, R., Greenbaum, S., Leech, G., \& Svartvik, J. (1985). A comprehensive grammar of the English language. London: Longman.

Swan, M. (1994). Design criteria for pedagogic language rules. In M. Bygate, A. Tonkyn, \& E. Williams (Eds.), Grammar and the language teacher (pp. 45-55). New York: Prentice Hall.

Turewicz, K. (2000). Applicability of cognitive grammar as a foundation of pedagogical/reference grammar. Łódź: Wydawnictwo Uniwersytetu Łódzkiego.

Tyler, A. (2008). Cognitive linguistics and second language instruction. In P. Robinson \& N. C. Ellis (Eds.), Handbook of cognitive linguistics and second language acquisition (pp. 456-488). New York: Routledge.

Tyler, A., \& Evans, V. (2001). The relation between experience, conceptual structure and meaning: Non-temporal uses of tense and language teaching. In M. Pütz, S. Niemeier, \& R. Dirven (Eds.), Applied cognitive linguistics I: Theory and language acquisition (pp. 63-105). Berlin: M outon de Gruyter.

Tyler, A., \& Evans, V. (2004). Applying cognitive linguistics to pedagogical grammar: The case of over. In M. Achard \& S. Niemeier (Eds.), Cognitive linguistics, second language acquisition, and foreign language teaching (pp. 257-280). Berlin: M outon de Gruyter.

Tyler, A., Mueller, C. M., \& Ho, V. (2010). Applying cognitive linguistics to instructed L2 learning: The English modals. In J. Littlemore \& C. JuchemGrundmann (Eds.), Applied cognitive linguistics in second language learning and teaching [Special issue]. AlLA Review, 23, 31-49.

Vendler, Z. (1957). Verbs and times, The Philosophical Review, 66, 143-160. 